\section{Effect of 5\% fluoride varnish application on caries among school children in rural Brazil: a randomized controlled trial}

Arruda AO, Senthamarai Kannan R, Inglehart MR, Rezende CT, Sohn W. Effect of $5 \%$ fluoride varnish application on caries among school children in rural Brazil: a randomized controlled trial. Community Dent Oral Epidemiol 2011. (C) 2011 John Wiley \& Sons A/S

Abstract - Objectives: To determine the efficacy of 5\% sodium fluoride (NaF) varnish application in reducing caries increments in the permanent dentition of rural Brazilian school children over the course of 12 months. Methods: A double-blind, randomized, placebo-controlled trial was conducted with 379 children aged 7-14 years who attended three schools in Brazil between January 2006 and December 2007. During this period, each school was visited four times at 6-month interval for recruitment, dental examinations, and fluoride varnish applications. Recruited children were randomly assigned to either a treatment ( $5 \% \mathrm{NaF}$ varnish, $n=198$ ) or a control group (placebo, $n=181$ ). Trained interviewers collected data on oral health habits and sociodemographic characteristics from the children. Information on the child's diet was collected through a 7-day food frequency diary. Caries examinations were conducted using the International Caries Detection and Assessment System (ICDAS). The efficacy of fluoride varnish application on caries prevention was reported as a preventive fraction (PF). Crude caries increments of decayed and filled surfaces (DFS) were compared between fluoride varnish and placebo groups. A generalized linear model (GLM) was constructed to test the differences in DFS increments between the groups after accounting for confounding factors. Results: Of the total sample $(N=379), 210(55.4 \%)$ children had completed 12 months of follow-up including one or two applications of fluoride varnish or placebo. At the baseline examination, the children in the treatment and control groups presented on average 6.2 and 5.6 DFS, respectively $(P<0.001)$. After 12 months of follow-up, the children in the varnish group showed significantly lower DFS increments than did children in the control group (10.8 versus 13.3; $P<0.007$ ), with PF of $40 \%$ (95\% CI: $34.3-45.7 \%$; $P<0.0001)$. Conclusions: The results of this study suggest that applications of $5 \% \mathrm{NaF}$ varnish can be recommended as a public health measure for reducing caries incidence in this high-caries-risk population.
Airton O. Arruda ${ }^{1}$, Raghavendra Senthamarai Kannan ${ }^{2}$, Marita R. Inglehart ${ }^{3}$, Cristiane T. Rezende ${ }^{4}$ and Woosung Sohn ${ }^{2}$

${ }^{1}$ Department of Orthodontics \& Pediatric Dentistry, University of Michigan, Ann Arbor, MI, USA, ${ }^{2}$ Department of Cariology, Restorative Sciences \& Endodontics, University of Michigan, Ann Arbor, MI, USA, ${ }^{3}$ Department of Periodontics \& Oral Medicine, University of Michigan, Ann Arbor, MI, USA, ${ }^{4}$ Division of Environmental Health, Department of Public Health, São Paulo, Brazil

Key words: Brazil; dental caries; fluoride varnishes; permanent dentition; randomized controlled trial

Woosung Sohn, Department of Health Policy and Health Services Research, Boston University Henry M. Goldman School of Dental Medicine, 560 Harrison Ave., 3rd floor, Boston, MA 02118, USA

Tel.: 6174141156

Fax: 6176386381

e-mail: woosung@bu.edu

Submitted 6 January 2011; accepted 20 October 2011
Dental caries is one of the most prevalent pandemic chronic infectious childhood diseases, which is amenable to prevention and management at both individual and population levels (1). According to the World Health Organization report in 2003, nearly $60-90 \%$ of school children and the majority of adults in industrialized nations had dental caries
(2). Although this high prevalence has declined dramatically over the past decade owing to the remarkable advances in evidence-based caries research and effective preventive practices, caries remains higher in some developing nations such as Brazil, China, Thailand, and Republic of Niger with the greatest impact falling on the poorest, under- 
privileged, certain ethnic minorities, and immigrant populations (3-5).

In Brazil, the average decayed, missing, and filled teeth (DMFT) index for children aged 12 years was 2.8 (higher than global average DMFT scores of 1.61) (6). Although the national prevalence rates have declined over the past three decades, these reductions are unevenly distributed among various geographical and socioeconomic groups (7-15). For example, the average DMFT scores for children aged 12 years residing in the southern and southeastern regions of Brazil ranged from 0.8 to 1.7 (7-9). In contrast, the children of the north, north Amazon and northeastern Brazil had DMFT scores ranged between 3.2 and 3.7 (13-15). These data suggest a great heterogeneity of the dental caries distribution. Studies that evaluated factors attributable for the decline and/or the polarization of the caries distribution indicated that low socioeconomic status (7-17), lack of access to dental care (16, 17), inequalities in access to fluoridated public water supplies (7-16, 18, 19), living in rural communities $(13,15,20)$, low maternal education $(20,21)$, and having poor dietary habits $(20,22)$ as the major determinants of dental decay. However, finding new and effective strategies to reduce disparities in caries experience remains a major challenge.

The Cochrane database has shown that topical fluoride applications are an effective way for preventing caries among children (23). Cochrane reviews comparing the relative effectiveness of different forms of topical fluoride interventions reported a substantial reduction in caries increments using fluoride toothpaste (24\%), mouth rinses (26\%), and gels (28\%) for both primary and permanent dentitions (24). The evidence is even stronger for professionally applied fluoride varnish. Twice-yearly applications of fluoride varnish have been shown to reduce decayed, missing, filled tooth surface (DMFS) increments by $46 \%$ for children and adolescents after a 1-year period (25). The benefits were even greater for highcaries-risk children (26). Moreover, the doseresponse relationships between the frequency of fluoride varnish applications and its efficacy on caries prevention were also evident in the literature (27-29). While four or more fluoride varnish applications per year are required to achieve maximum benefits, multiple applications of $\mathrm{NaF}$ varnish may not be feasible for low-come, rural children (30). Hence, regimens that apply high- concentration $\mathrm{NaF}$ varnish (say 5\%) once a year or semiannually may present a public health advantage over three or more applications per year. This trial tests the efficacy of $5 \% \mathrm{NaF}$ varnish application in preventing caries experiences in permanent dentition among underserved and/or underprivileged rural school children of southeastern Brazil. Additionally, a post hoc secondary analysis was conducted to explore the efficacy of once- versus twice-yearly applications of $\mathrm{NaF}$ varnish on caries reduction.

\section{Materials and methods}

Target population and study design

This study was conducted between June 2006 and December 2007 in Tapiratiba in southeastern Brazil. Tapiratiba is a small rural town of approximately 14000 people (2006) in the State of São Paulo. The local economy was traditionally centered on coffee and sugar cane production (31). Average monthly family income was Brazilian Reals R\$1512 (US\$ 879) (32), with $25.4 \%$ (range: $19-32 \%$ ) of residents were at or below poverty level (33). While this town has had a fluoridated public water supply since 1986 (0.7 ppm), owing to the topography of the water distribution areas, inequalities in the access to community water fluoridation exist, with people living on farms and in the hills having no access to fluoridated water.

This study was a prospective, randomized, parallel group, placebo-controlled, double-blind design that evaluated the efficacy of $5 \% \mathrm{NaF}$ varnish in preventing decayed and filled surfaces (DFS) increments among high-caries-risk children. The design and conduct of this trial was approved by the Institutional Review Board for the Health Sciences at the University of Michigan, Ann Arbor campus, MI. In addition, approvals from the Tapiratiba Mayor's office and the school administrations where this study was conducted were also obtained.

\section{Study sample and enrollment}

A priori power analysis performed with a desired alpha value of 0.05 , power of 0.80 , and anticipated $R^{2}$ of 0.05 to detect a difference of $10 \%$ DFS increments between the groups determined a minimum sample size of 85 children in each of the two groups. In anticipation of high attrition rates (say 50\%), the goal was to enroll approximately 170 children into each group. 
In an attempt to increase the level of participation, information about the study was shared with the local media and flyers were sent home with the children. During the parents meeting held 6 months prior to the start of the study, families were informed about the research and consent forms were disseminated. Children (6-14 years old) attending first through eighth grade were asked to participate in this trial. Parents were informed that their child's participation was voluntary and that they could withdraw from the study at anytime without consequences.

Inclusion criteria required that the child be enrolled in the Tapiratiba Children Oral Health Program and returned a signed parental consent form along with the child's written assent to participate. Children with a congenital orofacial anomaly such as cleft palate or cleft lip were excluded.

Figure 1 presents the Consort flow diagram tracking subject participation for the entire study. All children participating in this trial were recruited primarily at the two baseline visits (6 months apart - in June 2006 and December 2006) and were then followed over a period of
1 year from their initial baseline visits. A total of 528 children attending three rural schools were asked to participate in this trial. Of the three schools, one school (comprising 362 children) was located within the city limits and had access to city fluoridated water supply. The remaining two schools (82 and 84 children, respectively) were located outside the city limits and had no access to community water fluoridation. A total of 149 students failed to return signed parental consent forms and were excluded from study participation. The final cohort of 379 students was then randomly allocated to two parallel groups: $5 \% \mathrm{NaF}$ varnish $(n=198)$ and placebo $(n=181)$. In this study, all children were identified by their school identification (ID) number. The randomization was achieved on the basis of odd and even ID numbers by coin flipping. For example, children with odd ID numbers were assigned to one group, and the IDs with even numbers were allocated to the other group. All parents, children, and examiners were blinded to the group allocation and intervention status (double-blind study design).

At the end of the 12-month follow-up period, about $169(44.5 \%)$ children (85 in the treatment and

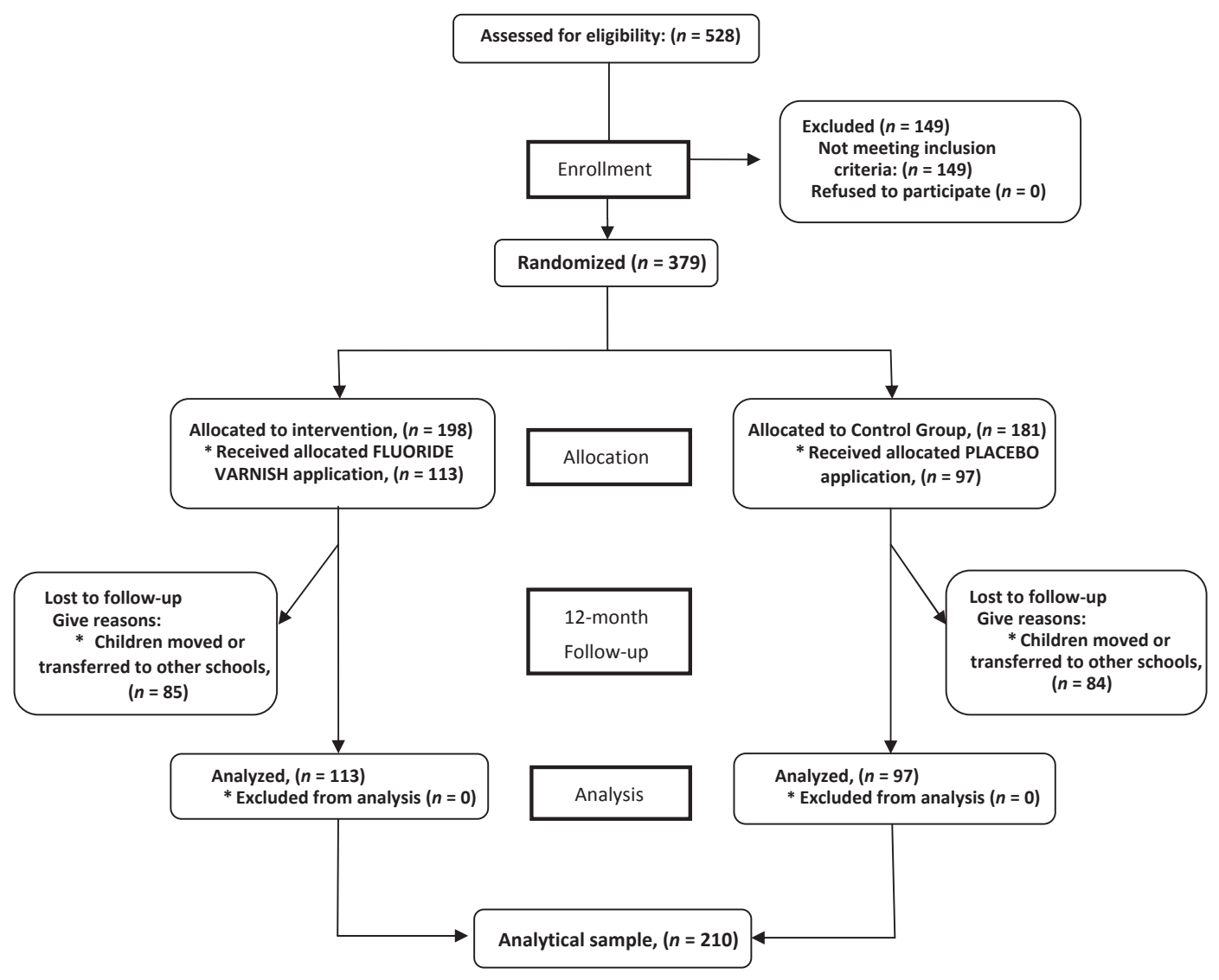

Fig. 1. Consort flowchart of the children screened for the study. 
84 in the control group) were lost to follow-up, resulting in an analytical sample size of 210 children (Fig. 1).

\section{Data collection}

An interviewer-administered questionnaire was used to collect information from children based on two domains: sociodemographic characteristics (age and gender) and oral health behavior (tooth brushing habits). Trained social workers conducted these interviews in Portuguese. In addition, a 7-day food frequency diary was distributed to the students 8 days prior to the interview. Students were requested to record all foods and drinks consumed in the diary on a regular basis for 1 week with the help of their caregiver prior to their interview. The questionnaire was initially translated into Portuguese by native speakers, then back-translated to English for the translation accuracy, and revised when necessary. Follow-up interviews were conducted at the 6- and 12-month visits to assess children's dietary patterns.

During school hours, four trained and calibrated dentists, using the International Caries Detection and Assessment System (ICDAS) criteria (34), performed caries assessment examinations using WHO probes and plane surface mirrors with students seated in portable dental units under standard operating light illumination. Data were collected solely on visual-tactile examination and no radiographs were taken. The dental examinations for caries status were limited to permanent dentition. Carious tooth surfaces were identified as ICDAS code ' 1 ' (indicative of first visual change in enamel) and higher (included both noncavitated and cavitated lesions). Crude caries experiences for the permanent teeth were recorded using the (DFS) scores. Missing tooth surfaces owing to caries were not included during the analysis (because of the lack of accuracy of assessing reasons for tooth loss in these mixed dentition ages). Prior to the start of the dental examination, all children brushed their teeth under trained social workers' supervision.

Examining dentists were trained and calibrated for the ICDAS criteria before the start of the baseline examination and recalibrated at each follow-up visit. To assess inter- and intra-examiner reliability, each examiner performed duplicate examinations on $10 \%$ of the study sample. Reexaminations were arranged in such a way that the examiners were blinded to which children would be examined. Inter-examiner reliability ranged between 0.73 and 0.81 (Cohen's kappa coefficient).
Intra-examiner reliability for the four examiners ranged between 0.59 and 0.93 .

\section{Fluoride varnish application protocol}

A 5\% NaF varnish (Cavity Shield ${ }^{\circledR}$ from OMNII Oral Pharmaceuticals, West Palm Beach, FL, USA) was used in this study. Both fluoride varnish and placebo were provided by the manufacturer in single-dose vials prelabeled with a number assigned to each child. The two formulations ( $\mathrm{NaF}$ varnish and placebo) were liquids that matched in taste, color, smell, and feel and were packaged by the manufacturer in vials which were identical in shape, color, and weight. The modes of administration were identical for all children. Throughout this trial, all children, parents, examining dentists, and research staff (e.g., recorders) remained blinded to group allocation and intervention status. The randomization records were opened only upon study completion. Prior to the examination, all children received oral health education about oral hygiene, followed by tooth brushing, and caries examinations. After the teeth were dried, the $\mathrm{NaF}$ varnish was applied to all tooth surfaces using a disposable brush and then air-dried. Both parents and children were provided with postapplication instructions to avoid solid foods for the first 4 hours after the application and to refrain from tooth brushing until the next morning. All interventions were performed twice (at the baseline visit and at the 6-month follow-up visit). The outcome measure (DFS scoring) was assessed at 0, 6, and 12 months.

Following the trial completion (at the 4 th visit in December 2007), all children at the participating schools, regardless of their group allocation, received $\mathrm{NaF}$ varnish.

\section{Statistical analyses}

SAS Version 9.3 (SAS Institute Inc., Cary, NC, USA) was used to perform statistical analysis. Descriptive analysis was conducted to summarize baseline sociodemographic characteristics and oral health status for each group. Categorical variables for the two groups were compared using Pearson's chisquare or Fischer's exact tests. The continuous variables were compared using Student's $t$-test. A $P$-value of $<0.05$ was considered statistically significant. The caries prevented fractions $(\mathrm{PF})$ were derived by calculating the difference between the incidence of DFS in the placebo group $\left(\mu_{\mathrm{c}}\right)$ and the incidence in the treatment group $\left(\mu_{\mathrm{t}}\right)$, divided by the incidence of DFS in the placebo group $\left[\mathrm{PF}=100\left(\mu_{\mathrm{c}}-\mu_{\mathrm{t}}\right) /\left(\mu_{\mathrm{c}}\right)\right]$ (35). The PF indicates the 
percentage reduction in caries incidence owing to varnish treatment relative to the incidence in the placebo group. The standard error (SE) of PF was also calculated according to the method presented by Zhang et al. (35):

$$
\mathrm{SE}=\sqrt{\left[\left\{\left(\mathrm{cv}_{\mathrm{t}}\right)^{2} \times\left(\mu_{\mathrm{t}}+\left(\mathrm{cv}_{\mathrm{c}}\right)^{2} \times\left(\mu_{\mathrm{c}}\right)\right\} \times\left(\mu_{\mathrm{t}} / \mu_{\mathrm{c}}\right)\right]\right.},
$$

where $\mathrm{cv}_{\mathrm{t}}$ and $\mathrm{cv}_{\mathrm{c}}$ are the coefficients of variation [which is defined as the standard deviation $(\sigma)$ divided by the mean, $\mu$ ] for the treatment and control groups, respectively. In the standard error (SE) equation, the $\mathrm{Cv}_{\mathrm{t}}$ and $\mathrm{Cv}_{\mathrm{c}}$ were calculated using the formula: $\mathrm{cv}_{\mathrm{t}}=\left(\sigma_{\mathrm{t}} / \mu_{\mathrm{t}}\right)$ and $\mathrm{cv}_{\mathrm{c}}=\left(\sigma_{\mathrm{c}} / \mu_{\mathrm{c}}\right)(35)$.

For data analysis purposes, new variables were created. A sugar consumption variable was created by summing the intake frequencies for cake and sugar confections from the 7-day food frequency diary, which was then dichotomized into: 'low sugar intake' (seven times or less sugar consumption per week) and 'high sugar intake' (more than seven times per week). Tooth brushing frequencies were categorized into: (i) never or seldom brushed teeth, (ii) brushes once a day, and (iii) brushes two times a day or more. Age was dichotomized as '<10 years old' and 'equal or older than 10 years' based on frequency distribution. In addition, a variable 'water fluoridation (yes versus no)' was created based on whether a student attended the school in the town (fluoridated) versus the two schools outside the town limits (nonfluoridated).

A generalized linear model (SAS PROC GLM) was fitted to estimate associations between the relevant variables and covariates in a multivariate environment, namely to evaluate the difference in the progression of average DFS increments over a 12-month period between the fluoride varnish and control group, after accounting for confounding by other covariates such as age, gender, brushing habit, consumption of cariogenic foods (cakes and confectioner's sugar intake), and access/no access to community water fluoridation.

Furthermore, a post hoc secondary analysis was performed to determine the effectiveness of the frequency of $\mathrm{NaF}$ varnish application (once-yearly versus semiannually) against placebo controls.

\section{Results}

A total of 210 study participants had a complete 12 months of follow-up data, representing an overall follow-up rate of 55.4\% (210/379) (Fig. 1). All subjects were aged 7-14 years (mean $=9.6$ years), $113(54 \%)$ were girls and $97(46 \%)$ were boys. The sociodemographic characteristics of these children in both groups were comparable at baseline (Table 1). The majority of children (59\%) attended a school with water fluoridation, with varnish group children (58.4\%) and control group children $(59.7 \%)$ being a likely to have access to fluoridated water at their school $(P=0.83)$. Nearly two-thirds of the respondents $(76 \%)$ reported brushing their teeth twice or more per day, with the proportion being higher $(78.7 \%)$ for the varnish group than the control group $(72.1 \%)(P=0.05)$. Of the 210 children who completed 12-month follow-

Table 1. Baseline characteristics of the study participants with a complete 12-month follow-up examination

\begin{tabular}{|c|c|c|c|c|}
\hline Variables & $N=210$ & Varnish $(n=113)$ & Control $(n=97)$ & $P$-value \\
\hline \multicolumn{5}{|l|}{ Age, years } \\
\hline Mean \pm SD & 210 & $9.62+1.36$ & $9.63+1.36$ & 0.54 \\
\hline Range & & $7-13$ years & 7-14 years & \\
\hline \multicolumn{5}{|l|}{ Gender, $n(\%)$} \\
\hline Males & $97(46)$ & $59(52.2)$ & $38(39.1)$ & 0.05 \\
\hline Females & $113(54)$ & $54(47.8)$ & $59(60.9)$ & \\
\hline \multicolumn{5}{|l|}{ School/water fluoridation, $n(\%)$} \\
\hline School 1 (fluoridated) & $124(59)$ & $66(58.4)$ & $58(59.7)$ & 0.84 \\
\hline Schools 2 \& 3 (nonfluoridated) & $86(41)$ & 47 (41.6) & 39 (40.3) & \\
\hline \multicolumn{5}{|l|}{ Brushing habit, $n(\%)$} \\
\hline Two or more times a day & $159(76)$ & $89(78.7)$ & $70(72.1)$ & 0.05 \\
\hline Once-daily & $25(12)$ & 15 (13.3) & $10(10.3)$ & \\
\hline None/couple of times a week & $26(12)$ & $9(8)$ & $17(17.6)$ & \\
\hline \multicolumn{5}{|l|}{ Sugar consumption, $n(\%)$} \\
\hline High & $129(61)$ & $60(53.1)$ & 69 (71.1) & 0.007 \\
\hline Low & $81(39)$ & $53(46.9)$ & $28(28.3)$ & \\
\hline
\end{tabular}


up, a greater percentage of the control group reported higher sugar consumption $(P=0.007)$.

Table 2 shows the average differences in DFS scores and 95\% confidence intervals between the groups. The average baseline DFS scores for the fluoride varnish group were higher than those of the control group (6.15 versus 5.59; $P=0.45$ ); however, this difference was not statistically significant. In contrast, at the 12-month follow-up examinations, children in the control group had significantly higher average DFS score when compared to children in the varnish group (13.31 versus $10.76 ; P<0.007)$. In addition, the observed difference in the average DFS increment of the fluoride varnish group was smaller (4.61) than that for the control group (7.72). Overall, the caries PF of 40\% (95\% CI: $34.3-45.7 \% ; P<0.0001$ ) was observed for children receiving fluoride varnish (after a 12 -month period). No adverse events were reported, and no trial participant was removed from the study owing to the complications associated with fluoride varnish application.

A post hoc secondary analysis was performed to assess the effectiveness of the frequency of fluoride varnish and placebo (semiannually versus once-yearly) applications. The results showed that children who received two applications of varnish within a year (at baseline and 6-month follow-up visit, $n=57$ ) had a significant influence on caries PF of $49.0 \%$ (95\% CI: 31.7-66.3\%; $P<0.0001)$ when compared to children with two placebo applications $(n=43)$, after 12-month period. In contrast, children who received a single dose of varnish application per year (i.e., only at baseline, $n=56$ ) had on average a $31 \%$ (95\% CI: $24.5-37.5 \%$ ) reduction in DFS increments in comparison with children with single placebo application $(n=54)$ over a 12 -month period, but this difference was not statistically significant $(P=0.26)$ (Table 2).

Table 3 summarizes the GLM ANOvA results from bivariate and adjusted models. The adjusted model shows that $5 \% \mathrm{NaF}$ varnish when applied either once or twice per year was effective in preventing the initiation of new caries lesions by 2.44 fewer DFS than placebo children after accounting for confounding $(P<0.008)$. The only other covariate that was significant in the fitted ANOvA model was sugar consumption. Children with high sugar intake (seven times a week or more) had on average 3.06 higher DFS increments than did children with low sugar intake, and this difference was statistically significant $(P=0.001)$. 
Table 3. Unadjusted and adjusted (generalized linear model ANOvA) models for age, gender and oral health-related characteristics and decayed and filled surfaces increments at the 12-months follow-up examination $(n=210)$

\begin{tabular}{|c|c|c|c|c|c|c|c|}
\hline \multirow[b]{2}{*}{ Variables } & \multirow[b]{2}{*}{$N=210$} & \multicolumn{3}{|c|}{$\begin{array}{l}\text { Crude (Unadjusted) } \\
\text { association } \\
\end{array}$} & \multicolumn{3}{|c|}{ Adjusted model } \\
\hline & & $\beta$ & SE & $P$-value & $\beta$ & SE & $P$-value \\
\hline \multicolumn{8}{|l|}{ Age, years } \\
\hline$<10$ years & 116 & 0.48 & 0.93 & 0.61 & 0.65 & 0.92 & 0.48 \\
\hline$\geq 10$ years (ref) & 94 & & & & & & \\
\hline \multicolumn{8}{|l|}{ Gender } \\
\hline Males & 97 & -0.63 & 0.92 & 0.49 & -0.34 & 0.91 & 0.71 \\
\hline Females (ref) & 113 & & & & & & \\
\hline \multicolumn{8}{|l|}{ School/water fluoridation } \\
\hline School 1 (Fluoridated) & 124 & -0.64 & 0.93 & 0.49 & -0.76 & 0.93 & 0.42 \\
\hline Schools 2 \& 3 (Nonfluoridated) (ref) & 86 & & & & & & \\
\hline \multicolumn{8}{|l|}{ Brushing habit } \\
\hline Two or more times a day & 159 & -1.85 & 1.42 & 0.19 & -0.67 & 1.38 & 0.63 \\
\hline Once-daily & 25 & -1.93 & 1.87 & 0.3 & -1.13 & 1.81 & 0.53 \\
\hline None/couple of times a week (ref) & 26 & & & & & & \\
\hline \multicolumn{8}{|l|}{ Sugar consumption } \\
\hline High (7+ times/week) & 129 & 3.46 & 0.92 & 0.0002 & 3.06 & 0.94 & 0.001 \\
\hline Low (7 or less/week) (ref) & 81 & & & & & & \\
\hline \multicolumn{8}{|l|}{ Varnish treatment } \\
\hline Varnish & 113 & -3.08 & 0.9 & 0.0007 & -2.44 & 0.92 & 0.008 \\
\hline Control (ref) & 97 & & & & & & \\
\hline
\end{tabular}

\section{Discussion}

Our study findings support the use of $5 \% \mathrm{NaF}$ varnish (Cavity Shield ${ }^{\circledR}$; OMNII Oral Pharmaceuticals) as a safe and effective topical agent in preventing early childhood caries and progression of DFS increments in permanent dentition among high-caries-risk children. The results demonstrated a tendency in the fluoride varnish group toward reduction in new DFS lesions and with a minimal increase in secondary DFS lesions. The crude caries $\mathrm{PF}$ of $41 \%$ among the varnish group was in agreement with the Zimmer et al. (36) study who reported a $37 \%$ reduction in DFS increments in permanent dentition with a biennial application of Duraphat $^{\circledR}$ (Colgate Oral Pharmaceuticals, NewYork, NY, USA) fluoride varnish after 4 years of follow-up. Similarly, randomized controlled studies conducted by Weintraub et al. (29), Holve et al. (37), and Lawrence et al. (38) assessing the efficacy of semiannual application of $5 \% \mathrm{NaF}$ varnish in primary dentition showed overall DMFS reductions of $50 \%, 35 \%$, and $18 \%$, respectively, over a period of 2 years depending on the target population characteristics.

Results from our post hoc secondary analysis showed that two fluoride varnish applications per year were more efficacious than one application. Although the magnitude of caries experience with once-yearly application of varnish reduced DFS by
1.37 increments when compared to placebo controls $(\mathrm{PF}=32 \%)$, the results were not statistically significant $(P=0.26)$. While it might be beneficial to provide three or more applications in a year to high-caries-risk children in community-based programs, this might be more difficult to provide to communities with less dental access. The findings of this study support one or two applications of high concentrations (5\%) of fluoride varnish as an effective method to prevent caries incidence and progression in this high-caries-risk underserved population.

Although Tapiratiba's community water fluoridation level was $0.7 \mathrm{ppm}$, the inequalities in the access to fluoridated water supply among socioeconomically deprived communities within the town were apparent. In addition, the DFS experience was unevenly distributed across populations with unequal (limited or no) access to fluoridated drinking water. On average, children with partial exposure to fluoridated water supply showed 0.64 fewer DFS than children with no access to water fluoridation although the difference was not statistically significant $(P=0.49)$. This finding was supported by the literature from Brazil (18) and United States (39) with regard to water fluoridation and oral health equity. Moreover, this study estimates the DFS experience and PF (Table 3) as the true effects of fluoride varnish after accounting for confounding owing to water fluoridation. 
Our prospective study also demonstrates a positive correlation between sugar consumption and DFS increments. Both the frequency of sugar consumption and DFS increment were highest among these less-affluent children. The ANOvA model suggests that children with high sugar consumption invariably demonstrated significantly higher DFS increments irrespective of their intervention status compared to children with low sugar consumption $(P=0.001)$. A similar relationship was observed by Mobley et al. (40) who found an overwhelming association between sugar consumption and dental caries. Nearly a quarter $(24 \%)$ of our study participants brushed their teeth once a day or less. Given the participants' high DFS risk status, we recommend supervised tooth brushing with fluoridated toothpaste on each school day (41). Owing to the barriers to improving access to dental care, the high levels of untreated caries in this study population emphasize the need to promote selfcare oral health education, specifically focusing on the negative effects of high sugar consumption and the impact of good oral hygiene habits on caries development (42).

Limitation of this study includes high attrition rates $(44.6 \%)$. Of the initial study sample $(N=396)$ at the baseline examination, 169 children were randomly lost to follow over the course of 12 months. Because the dropout rates were similar across the study groups (Varnish $=85$, placebo $=84$ ), further analysis to assess whether dropout rates differed significantly between participants was not performed. However as an attempt to address this heterogeneity, covariate adjustment was established by adjusting for baseline characteristics in the ANOva model. Despite efforts to promote attendance to school for followup appointments, this trial suffered a high attrition rate. For example, transportation to the school was offered in an attempt to obtain high school attendance on examination days predicted to have bad weather. In spite of all efforts, the response rate was only $55.4 \%$, which might be attributed to the transitory characteristics of the target population which were primarily migrant farm workers. During the study period, many children moved with their families and transferred to other schools. Although preventive services were offered to the study population at large, a vast majority of participants did not take advantage of the program, most likely because the majority of parents of these children faced numerous challenges that might interfere with the completion of a long-term preventive regimen.

In summary, it can be concluded that one or two applications per year of $5 \% \mathrm{NaF}$ varnish can be used as an effective caries preventive measure for high-caries-risk children. In addition, the high levels of untreated caries among these study participants emphasize the need for oral health education, especially concerning the negative effects of high sugar consumption on caries development. Furthermore, the findings of this randomized controlled trial should be used to raise awareness for the importance of planning and successful implementation and improvement of effective school-based oral health promotion programs.

\section{Acknowledgements}

This project was funded by University of Michigan Office of Vice President and Research Faculty Grants and Awards program funding and by A.O. Arruda Foundation - Ribeirao Preto (Sao Paulo, Brazil). We thank Mr. Joao Carlos de Oliveira (Mayor of Tapiratiba, Sao Paulo, Brazil) for his generous support.

\section{References}

1. Edelstein BL. The dental caries pandemic and disparities problem. BMC Oral Health 2006;6(Suppl 1):S2.

2. Petersen PE. The World Oral Health Report 2003: continuous improvement of oral health in the 21st century - the approach of the WHO Global Oral Health Programme. Commun Dent Oral Epidemiol 2003;31(Suppl 1):3-24.

3. Petersen PE, Bourgeois D, Ogawa H, Estupinan-Day $S$, Ndiaye $C$. The global burden of oral disease and risks to oral health. Bull World Health Organ 2005;83:661-9.

4. World Health Organization. Oral health database global DMFT for 12-year-old: 2004. WHO regions: Global. Available at: http://www.mah.se/CAPP/ Country-Oral-Health-Profiles / According-to-Alphabeti cal/Global-DMFT-for-12-year-olds-2004 [last accessed 07 November 2011].

5. Marthaler TM. Changes in dental caries 1953-2003. Caries Res 2004;38:173-81.

6. World Health Organization. Oral health database global DMFT for 12-year-old: 2004. WHO regions: AMRO: Brazil. Available at: http:/ / www.mah.se/CAPP/ Country-Oral-Health-Profiles/According-to-Alphabetical /Global-DMFT-for-12-year-olds-2004 [last accessed 07 November 2011].

7. Traebert J, Lacerda JT, Fischer TK, Junbo Y. Dental caries and orofacial pain trends in 12-year-old school children between 1997 and 2003. Oral Health Prev Dent 2005;3:243-8. 
8. Constante HM, Bastos JL, Peres MA. Trends in dental caries in 12- and 13-year-old school children from Florianópolis between 1971 and 2009. Braz J Oral Sci 2010;9:410-4.

9. Tagliaferro EP, Meneghim MC, Ambrosano GM, Pereira AC, Sales-Peres SH, Sales-Peres A et al. Distribution and prevalence of dental caries in Bauru, Brazil, 1976-2006. Int Dent J 2008;58:75-80.

10. Cypriano S, Hoffmann RH, de-Sousa ML, Wada RS. Dental caries experience in 12-year-old school children in Southeastern Brazil. J Appl Oral Sci 2008;16:286-92.

11. Gushi LL, Rihs LB, Soares MC, Forni TI, Vieira V, Wada RS et al. Dental caries and treatment needs in adolescents from the state of São Paulo, 1998 and 2002. Rev Saude Publica 2008;42:480-6.

12. Martins RJ, Garbin CA, Garbin AJ, Moimaz SA, Saliba O. Declining caries rate in a municipality in Northwestern São Paulo State, Brazil, 1998-2004. Cad Saude Publica 2006;22:1035-41.

13. Medina W, Hurtig AK, San-Sebastián M, Quizhpe E, Romero C. Dental caries in 6-12-year-old indigenous and non-indigenous schoolchildren in the Amazon basin of Ecuador. Braz Dent J 2008;19:83-6.

14. Tobias R, Parente RCP, Rebelo MAB. Prevalence of dental caries and treatment needs among 12-year-old children in a small-sized municipality in the Amazon region. Rev Bras epidemiol 2008;11:1-10.

15. Sampaio FC, Freitas CH, Cabral MB, Machado AT. Dental caries and treatment needs among indigenous people of the Potiguara Indian reservation in Brazil. Rev Panam Salud Publica 2010;27:246-51.

16. Antunes JL, Narvai PC, Nugent ZJ. Measuring inequalities in the distribution of dental caries. Community Dent Oral Epidemiol 2004;32:41-8.

17. Baldani MH, Vasconcelos AG, Antunes JL. Association of the DMFT index with socioeconomic and dental services indicators in the state of Paraná, Brazil. Cad Saude Publica 2004;20:143-52.

18. Gabardo MC, da-Silva WJ, Olandoski M, Moysés ST, Moysés SJ. Inequalities in public water supply fluoridation in Brazil: an ecological study. BMC Oral Health 2008;8:9-16.

19. Sales-Peres SH, Bastos JR. An epidemiological profile of dental caries in 12-year-old children residing in cities with and without fluoridated water supply in the central western area of the state of São Paulo, Brazil. Cad Saude Publica 2002;18:1281-8.

20. Oliveira LB, Sheiham A, Bönecker M. Exploring the association of dental caries with social factors and nutritional status in Brazilian preschool children. Eur J Oral Sci 2008;116:37-43.

21. Traebert J, Guimarães LA, Durante EZ, Serratine AC. Low maternal schooling and severity of dental caries in Brazilian preschool children. Oral Health Prev Dent 2009;7:39-45.

22. Sampaio FC, Hossain AN, Vonder-Fehr FR, Arneberg P. Dental caries and sugar intake of children from rural areas with different water fluoride levels in Paraíba, Brazil. Community Dent Oral Epidemiol 2000;28:307-13.

23. Marinho VC. Cochrane reviews of randomized trials of fluoride therapies for preventing dental caries. Eur Arch Paediatr Dent 2009;10:183-91.
24. Marinho VC, Higgins JP, Sheiham A, Logan S. One topical fluoride (toothpastes, or mouthrinses, or gels, or varnishes) versus another for preventing dental caries in children and adolescents. Cochrane Database Syst Rev 2004;1:CD002780.

25. Marinho VC, Higgins JP, Logan S, Sheiham A. Fluoride varnishes for preventing dental caries in children and adolescents. Cochrane Database Syst Rev 2002;3:CD002279.

26. Seppä L. Studies of fluoride varnishes in Finland. Proc Finn Dent Soc 1991;87:541-7.

27. Weintraub JA. Fluoride varnish for caries prevention: comparisons with other preventive agents and recommendations for a community-based protocol. Spec Care Dentist 2003;23:180-6.

28. Azarpazhooh A, Main PA. Fluoride varnish in the prevention of dental caries in children and adolescents: a systematic review. Tex Dent J 2008;125: 318-37.

29. Weintraub JA, Ramos-Gomez F, Jue B, Shain S, Hoover CI, Featherstone JD et al. Fluoride varnish efficacy in preventing early childhood caries. J Dent Res 2006;85:172-6.

30. Ensor T, Cooper S. Overcoming barriers to health service access: influencing the demand side. Health Policy Plan 2004;19:69-79.

31. IBGE. Sample results of the census 2000 - Brazil's municipal digital network in 2001. Rio de Janeiro: IBGE; 2004; available at: IBGE Reference Online. http: / / www.ibge.gov.br/cidadesat/topwindow.htm?1 [last accessed 31 August 2010].

32. IBGE. Demographic census 2000 and expenditure survey - POF 2002/2003. Available at: IBGE Reference Online. http://www.ibge.gov.br/cidadesat/ topwindow.htm?1 [last accessed 31 August 2010].

33. IBGE. Medical health 2005; Brazil's municipal digital network in 2005. Rio de Janeiro: IBGE, 2006; available at: IBGE Reference Online. http:/ / www.ibge.gov.br/ cidadesat/topwindow.htm?1 [last accessed $31 \mathrm{Au}-$ gust 2010].

34. Ismail AI, Sohn W, Tellez M, Amaya A, Sen A, Hasson $\mathrm{H}$ et al. The International Caries Detection and Assessment System (ICDAS): an integrated system for measuring dental caries. Community Dent Oral Epidemiol 2007;35:170-8.

35. Zhang Q, Van-Palenstein-Helderman WH, Van'tHof MA, Truin GJ. Chlorhexidine varnish for preventing dental caries in children, adolescents and young adults: a systematic review. Eur J Oral Sci 2006;114:449-55.

36. Zimmer S, Robke FJ, Roulet JF. Caries prevention with fluoride varnish in a socially deprived community. Community Dent Oral Epidemiol 1999;27:103-8.

37. Holve S. An observational study of the association of fluoride varnish applied at well child care visits can reduce early childhood caries in American Indian children. Matern Child Health J 2008;12(Suppl 1): 64-7.

38. Lawrence HP, Binguis D, Douglas J, McKeown L, Switzer B, Figueiredo R et al. A 2-year community randomized controlled trial of fluoride varnish to prevent early childhood caries in Aboriginal children. Community Dent Oral Epidemiol 2008;36: 503-16. 
Arruda et al.

39. Burt BA. Fluoridation and social equity. J Public Health Dent 2002;62:195-200.

40. Mobley C, Marshall TA, Milgrom P, Coldwell SE. The contribution of dietary factors to dental caries and disparities in caries. Acad Pediatr 2009;9:410-4.

41. Curnow MM, Pine CM, Burnside G, Nicholson JA, Chesters RK, Huntington E. A randomized con- trolled trial of the efficacy of supervised tooth brushing in high-caries-risk children. Caries Res 2002;36:294-300.

42. Sohn W, Ismail A, Amaya A, Lepkowski J. Determinants of dental care visits among low-income African-American children. J Am Dent Assoc 2007;138:309-18. 